\title{
Signs and symptoms in patients with salivary gland hypofunction
}

\author{
LP Longman, SM Higham, R Bucknall, SB Kaye, WM Edgar, EA Field
}

\begin{abstract}
Summary
Salivary gland hypofunction can have a devastating effect on oral health and may be an indicator of systemic disease such as Sjögren's syndrome. This prospective study investigates the oral and non-oral signs and symptoms in 120 patients with objective evidence of salivary gland hypofunction (ie, an unstimulated whole salivary flow of $<0.2 \mathrm{ml} / \mathrm{min}$ ). Patients were questioned about symptoms associated with decreased oral function; non-oral symptoms were also noted. The underlying cause of salivary gland hypofunction was established on the basis of clinical and laboratory findings and further investigations.
\end{abstract}

Eighty-five per cent of patients reported symptoms of decreased oral function in addition to oral dryness. Non-oral signs and symptoms were reported by 106 patients. Fifty-three per cent of patients were diagnosed as having Sjögren's syndrome. The prevalence of the following non-oral signs and symptoms were significantly higher in patients with Sjögren's syndrome, than in those without; a history of dry/irritated eyes, salivary gland swelling, dry skin and reduced lacrimal flow. Salivary gland hypofunction is associated with a wide range of oral and non-oral signs and symptoms. Several of these are of potential value as triggers for the clinician to identify patients with Sjögren's syndrome, and should serve to prompt referral for specialist investigation.

Keywords: salivary gland hypofunction, xerostomia, systemic disease, Sjögren's syndrome

Department of Clinical Dental Sciences, The

Liverpool University

Dental Hospital and

School of Dentistry,

Liverpool L69 3BX, UK

LP Longman

SM Higham

WM Edgar

EA Field

Royal Liverpool

University Hospital

Trust, Liverpool $\mathbf{L} 7$

8XP, UK

R Bucknall

SB Kaye

Accepted 30 April 1996
Diminution of salivary flow is detrimental to oral health, and may compromise the psychological and social well being of the patient. Identification of salivary gland hypofunction is important, not only as an indicator of systemic diseases such as Sjögren's syndrome, but also because it is essential to prevent and manage the complications of reduced salivary flow, such as dental caries, impaired oral function and oral candidosis.

Xerostomia (the perception of oral dryness) is not a reliable indicator of salivary gland hypofunction, ${ }^{1}$ as some patients, who complain of a dry mouth, do not have evidence of reduced salivary flow. In common with salivary gland dysfunction, however, patients with xerostomia rarely complain of oral dryness as a solitary symptom, it is frequently associated with a wide range of oral and non-oral symptoms.

The principle aim of this prospective study was to document the oral and non-oral signs and symptoms in 120 patients with objective evidence of salivary gland hypofunction. This group of patients were subsequently investigated to establish possible underlying causes of their salivary gland hypofunction. A further objective was to ascertain whether there was a significant difference between the presentation of signs and symptoms in patients with Sjögren's syndrome and those in whom the diagnosis was not made. Early recognition of abnormalities associated with salivary gland hypofunction will enable medical and dental practitioners to identify patients who require referral to specialist units for further investigations.

\section{Materials and methods}

\section{PATIENTS}

One hundred and twenty patients attending a xerostomia clinic over a three-year period who complained of oral dryness and had objective evidence of salivary gland hypofunction, as ascertained by sialometry, were included in this study.

\section{CLINICAL HISTORY}

A detailed medical and drug history was elicited from every patient, this included a questionnaire to assess oral symptoms (table 1). The duration of xerostomia and any history of salivary gland symptoms was noted. Ophthalmological symptoms of dry or irritable eyes were recorded together with any dryness of the skin and vagina. Connective tissue disorders such as rheumatoid arthritis were also noted. Clarification was sought from the patients' general practitioner if there was uncertainty about the medical history.

\section{CLINICAL EXAMINATION}

A systematic orofacial examination was carried out, which included a clinician's subjective assessment of oral dryness, whereby the oral mucosa was categorised as normal (moist) or dry with little or no visible saliva. Clinical evidence of oral candidosis was supplemented by microbiological investigations. The dentition was examined but, for the purposes of this study, only the presence or absence of teeth 
Table 1 Oral symptoms in Sjögren's and non-Sjögren's patients with salivary gland hypofunction

\begin{tabular}{llll}
\hline & \multicolumn{3}{l}{ Number of patients with positive response (\%) } \\
\cline { 2 - 4 } Question & $\begin{array}{l}\text { Total } \\
(n=120)\end{array}$ & $\begin{array}{l}\text { Sjögren's } \\
(n=64)\end{array}$ & $\begin{array}{l}\text { Non-Sjögren's } \\
(n=56)\end{array}$ \\
\hline 1 Does your mouth feel dry \\
$\begin{array}{l}\text { when you eat a meal? } \\
\text { Do you frequently sip }\end{array}$ & $71(60)$ & $47(64)^{\star \star}$ & $24(43)$ \\
$\begin{array}{l}\text { liquids when you eat a meal? } \\
3 \text { Do you have difficulties } \\
\text { swallowing any foods? }\end{array}$ & $65(70)$ & $55(86)^{\star \star}$ & $30(54)$ \\
4 Is your mouth often sore? & $43(36)$ & $46(62)^{\star \star}$ & $20(36)$ \\
\hline
\end{tabular}

$\star$ modified from ${ }^{9} ;{ }^{\star \star}$ significant at $\mathrm{p}<0.001$

was noted. A preliminary estimate of lacrimal flow was made for all patients using a Schirmer I-test.

\section{SIALOMETRY}

Unstimulated and stimulated whole saliva flow rates were determined, under standardised conditions, using methods described by Sreebny and Valdini. ${ }^{2}$ Patients were instructed to refrain from eating, drinking or smoking for at least two hours prior to collection of saliva. Whole unstimulated (resting) saliva flow rates were measured by asking the patient to sit in a quiet room, head slightly down and not to swallow, but to spit the accumulated saliva into a receiving tube over a period of five minutes. Stimulated flow rates were measured in a similar way whilst the patient chewed a small piece of paraffin (Orion Diagnostica, Espoo, Finland). The volume of saliva was estimated by weighing the tube before and after collection. An unstimulated flow rate of less than 0.2 $\mathrm{ml} / \mathrm{min}$ and a stimulated flow of less than 0.5 $\mathrm{ml} / \mathrm{min}$ were considered to be abnormal and indicative of salivary gland hypofunction.,

\section{SCINTIGRAPHY}

Scintigraphy (radioisotopic study of salivary gland function using technetium pertechnetate, ${ }^{99 \mathrm{~m}} \mathrm{Tc}$, injected intravenously) was arranged for all patients to detect any functional abnormality in the major salivary glands. ${ }^{5-7}$

\section{LABORATORY INVESTIGATIONS}

Blood samples were collected for haematological (full blood count, erythrocyte sedimentation rate and film, serum and red cell folate, serum ferritin, serum vitamin $B_{12}$ concentrations) and immunological screening (serum immunoglobulins, rheumatoid and antinuclear factors, anti-Sjögren's syndrome-A and -B autoantibodies). Routine urinalysis was also undertaken; if an abnormal result was obtained the test was repeated. A fasting blood glucose concentration followed by a glucose tolerance test were requested if appropriate. Patients suspected of having diabetes or other systemic disease, such as Sjögren's syndrome, were referred for further investigations.

\section{FURTHER INVESTIGATIONS}

Labial gland biopsy was undertaken for patients with an equivocal diagnosis of Sjögren's syndrome. Minor salivary glands from inside the lower lip were harvested under local anaesthesia and examined microscopically for evidence of autoimmune sialadenitis.

Patients who were suspected of having structural abnormalities of the parotid or submandibular glands underwent sialography. This involved the infusion of an oil-based, radio-opaque contrast medium into the main duct of the salivary gland in question. Patients with persistent salivary gland swelling had computed tomography or magnetic resonance imaging.

\section{OPHTHALMOLOGICAL EXAMINATION}

Patients with a positive Schirmer test or subjective symptoms of dry or irritated eyes were assessed by an ophthalmologist. This included an evaluation of the conjuctival and corneal epithelium and tear film, height and appearance of the inferior and superior tear menisci, tear break up time, Rose Bengal stain and Schirmers test. Patients with blepharitis were treated and then re-evaluated.

\section{RHEUMATOLOGICAL ASSESSMENT}

All patients suspected of having secondary Sjögren's syndrome were fully assessed by a rheumatologist.

\section{AETIOLOGY OF SALIVARY GLAND HYPOFUNCTION}

The underlying cause of the salivary gland hypofunction was established, where possible, based on clinical and laboratory findings. Four diagnostic groups were established: Sjögren's syndrome (primary and secondary), therapeutic irradiation, drug-induced and idiopathic. A diagnosis of primary and secondary Sjögren's syndrome was made according to the proposed European criteria. ${ }^{7}$ Medication was considered to be the probable cause of xerostomia, when the onset of oral dryness was associated with the administration of xerogenic drugs, and other aetiological factors were absent.

\section{STATISTICAL ANALYSIS}

The presence or absence of oral and non-oral signs and symptoms was recorded and analysed using the Chi-square and Fisher's Exact probability tests using the SAS system ${ }^{8}$. The purpose of the analysis was to see if any of the signs and symptoms were more likely to occur in patients with Sjögren's syndrome, than in those without it. Differences were considered to be significant if $\mathrm{p}<0.05$.

\section{Results}

Most (105) of the patients were female. The age range was $25-89$ years (median 60 years).

\section{ORAL SYMPTOMS}

Of the 120 patients: 37 had experienced dryness for between six months and one year; 63 for between one and 10 years and 20 patients for 10 years or more. The majority of patients (84) had some remaining teeth; only 36 patients were edentulous.

All patients had a subjective feeling of dry mouth and 102 of these reported additional 
Table 2 Non-oral symptoms in Sjögren's and non-Sjögren's patients with salivary gland hypofunction

\begin{tabular}{|c|c|c|c|}
\hline \multirow[b]{2}{*}{$\begin{array}{l}\text { Clinical } \\
\text { history }\end{array}$} & \multicolumn{3}{|c|}{$\begin{array}{l}\text { Number of patients with a positive } \\
\text { response (\%) }\end{array}$} \\
\hline & $\begin{array}{l}\text { Total } \\
(n=120)\end{array}$ & $\begin{array}{l}\text { Sjögren's } \\
(n=64)\end{array}$ & $\begin{array}{l}\text { Non-Sjögren's } \\
(n=56)\end{array}$ \\
\hline $\begin{array}{l}\text { Salivary gland } \\
\text { swelling }\end{array}$ & $34(28)$ & $26(41)^{\star}$ & $8(14)$ \\
\hline Dry/irritated eyes & $70(58)$ & $58(91)^{\star \star}$ & $12(21)$ \\
\hline Dry skin & $65(54)$ & $51(80)^{\star \star}$ & $14(25)$ \\
\hline Vaginal dryness $^{\dagger}$ & $41(34)$ & $33(54)$ & $8(14)$ \\
\hline
\end{tabular}

*significant at $\mathrm{p}<0.05 ; \star \star$ significant at $\mathrm{p}<0.001$

$\dagger 105$ women were asked this question, 61 of whom had Sjögren's syndrome

Table 3 Oral and ophthalmological signs of Sjorgren's and nonSjogren's patients with salivary gland hypofunction

\begin{tabular}{llll}
\hline \multicolumn{4}{c}{ Number of patients (\%) } \\
\cline { 2 - 4 } Signs & $\begin{array}{l}\text { Total } \\
(n=120)\end{array}$ & $\begin{array}{l}\text { Sjogren's } \\
(n=64)\end{array}$ & $\begin{array}{l}\text { Non-Sjogren's } \\
(n=56)\end{array}$ \\
\hline $\begin{array}{l}\text { Clinician's subjective assessment of oral mucosa: } \\
\text { normal (moist) }\end{array}$ & $\begin{array}{l}\text { 34 (28) } \\
\text { dry }\end{array}$ & $12(19)$ & $22(30)$ \\
$\begin{array}{l}\text { Clinical evidence of: } \\
\text { reduced lacrimal flow* } \\
\text { orofacial candidosis }\end{array}$ & $58(48)$ & $52(81)$ & $34(61)$ \\
\hline
\end{tabular}

^Schirmer test; ${ }^{\star \star}$ significant at $\mathrm{p}<0.001$

Table 4 Aetiology of salivary gland hypofunction

\begin{tabular}{ll}
\hline Diagnosis or probable cause & Number of patients \\
\hline Sjögren's syndrome: & \\
primary & 38 \\
possible primary & 4 \\
secondary & 22 \\
Therapeutic irradiation & 3 \\
Drug induced & 16 \\
Idiopathic & 37 \\
\hline
\end{tabular}

oral symptoms (table 1). Statistical analysis showed there to be a significant difference $(p<0.001)$ between the responses to questions 1,2 and 3 in Sjögren's and non-Sjögren's patients. Individuals who gave a positive response to questions 1,2 or 3 had a much greater likelihood of having Sjögren's syndrome than patients who did not present with this symptom $(p<0.001)$. Several non-oral signs and symptoms (table 2) were more likely to occur in patients with Sjögren's syndrome, than those who did not have this condition, they were: salivary gland swelling, dry/irritable eyes, dry skin and a reduced lacrimal flow ( $p$ $<0.05$ ).

Table 3 records details of oral and nonophthalmological signs. Fifty-eight patients had evidence of a reduced lacrimal flow as indicated by a positive Schirmer test; $90 \%$ of these patients had complained of dry/gritty eyes.
The aetiology of salivary gland hypofunction is shown in table 4. Over half of the patients (53\%) were diagnosed as having Sjögren's syndrome. A diagnosis of secondary Sjögren's syndrome was made in 22 patients; 14 of these had rheumatoid arthritis, other connective tissue diseases included: systemic lupus (three), systemic sclerosis (three) and primary biliary cirrhosis (three). Iatrogenic causes were attributed as the probable cause for salivary gland hypofunction in 19 patients. Two of the three subjects in the therapeutic irradiation group had received radioactive iodine for thyroid cancer; the other underwent external beam radiotherapy for lymphoma. No objective, identifiable cause could be found in 37 patients.

\section{Discussion}

The results of this study confirm that salivary gland hypofunction is often associated with a wide range of oral and non-oral signs and symptoms. Oral dryness was reported as a solitary oral symptom by only $18(15 \%)$ patients; $85 \%$ had at least one additional oral symptom, as ascertained by a positive response to questions 1,2 or 3 (table 3 ). These questions, which indicate impaired oral function, were adapted from Fox et $a l^{9}{ }^{9}$ and have been shown to be highly predictive of salivary gland hypofunction. 9 This study has established that a positive response to any of these questions was more likely in patients with Sjögren's syndrome, than patients who did not have this disease. The aetiology of salivary gland hypofunction in the 100 dry mouth patients studied by Fox et $a l^{9}{ }^{9}$ was not published. Question 4 (is your mouth often sore?) was included in this study because mucositis maybe a complication of xerostomia. The frequency with which this symptom occurred was similar for both groups of patients. This is not an unexpected finding as several systemic and local conditions can cause a generalised sore mouth. ${ }^{10}$

Salivary gland hypofunction, for the purposes of this study, was defined as an unstimulated whole salivary flow rate of $<0.2$ $\mathrm{ml} / \mathrm{min}$, as this figure has been suggested by other workers in the field. ${ }^{3,11}$ It is important to appreciate that unstimulated flow rates vary widely between subjects, and it can be difficult to always judge whether an individual has a reduced flow or not. However, if sialometry is undertaken at frequent intervals it may be possible to detect changes in the severity of salivary gland hypofunction.

An unstimulated flow rate of $0.1 \mathrm{ml} / \mathrm{min}$ has been suggested as one of the diagnostic criteria for Sjögren's syndrome, according to the European Study group (box 1), ${ }^{7}$ and this figure was used in this present study. This value, however, is probably overly low when defining salivary gland hypofunction in a population with a number of different causes. Whole saliva flow was measured in the present study as opposed to measuring flow from single glands. Whole saliva is easily obtained and, provided it is collected under standardised 


\section{Preliminary criteria for the}

classification of Sjögren's syndrome (adapted from Vitali et $a^{7}$ )

1 Ocular symptoms

Definition: a positive response to at least one of the following questions:

- have you had daily, persistent, troublesome dry eyes for more than three months?

- do you have a recurrent sensation of sand or gravel in the eyes?

- do you use tear substitutes more than three times day?

\section{Oral symptoms}

Definition: a positive response to at least one of the following questions:

- have you had a daily feeling of dry mouth for more than three months?

- have you had recurrent or persistently swollen salivary glands as an adult?

- do you frequently drink liquids to aid swallowing dry foods?

3 Ocular signs

Defintion: objective evidence of ocular involvement determined on the basis of a positive result on at least one of the following tests:

- Schirmer-1 test ( $\leqslant 5 \mathrm{~mm}$ in $5 \mathrm{~min}$ )

- Rose Bengal score ( $\geqslant 4$, according to the van Bijsterveld scoring system)

\section{Histopathologic features}

Definition: focus $\geqslant 1$ on minor salivary gland biopsy (focus defined as an agglomeration of at least 50 mononuclear cells; focus score defined as the number of foci $4 \mathrm{~mm}^{2}$ of glandular tissue).

\section{Salivary gland involvement}

Definition: objective evidence of salivary gland involvement, determined on the basis of a positive result on at least one of the following tests:

- salivary scintigraphy

- parotid sialography

- unstimulated salivary flow ( $\leqslant 1.5 \mathrm{ml}$ in 15 $\min$ )

6 Auto-antibodies

Definition: presence of at least one of the following serum auto-antibodies:

- antibodies to Ro/SS-A or LA SS-B antigens

- antinuclear antibodies

- rheumatoid factor

Exclusion criteria: pre-existing lymphona, acquired immunodeficiency syndrome, sarcoidosis, or graftversus-host disease.

Possible primary Sjögren's syndrome $=$ three positive responses from three different categories Definite primary Sjögren's syndrome $=$ four positive responses from four different categories Definitive secondary Sjögren's syndrome = one positive response from questions 1 or 2 and two positive responses to questions 3,4 or 5 (ie, three responses from three different categories; excluding category 6 ) in the presence of a connective tissue disease.

Box 1

conditions, is a good indicator of whole mouth dryness ${ }^{4}$. Salivary flow meters are now commercially available for use in specialist clinics and dental practice (Sialometer Pro Flow ${ }^{\text {TM }}$ Inc, New York, USA). More recently a fluoride dilution method has been suggested for the measurement of salivary volume, ${ }^{12}$ this

\section{Summary points}

- saliva is important for the maintenance of oral health and the psychological and social wellbeing of the patient

- patients complaining of xerostomia should be questioned about further symptoms indicative of reduced oral function

- salivary gland hypofunction can be an indicator of systemic disease such as Sjögren's syndrome

- salivary gland hypofunction is associated with many oral and non-oral signs and symptoms, the following are strongly suggestive of Sjögren's syndrome: oral dysfunction, dry/ irritated eyes, dry skin, vaginal dryness, reduced lacrimal flow and a history of salivary gland swelling

- patients suspected of having salivary gland hypofunction should be referred for specialist investigation

Box 2

technique, however, is more expensive and labour intensive than the collection of whole saliva as described in this study. In addition, the accuracy of the fluoride dilution assay in the estimation of salivary volume and, more importantly, saliva flow rates in patients with salivary gland hypofunction, needs to be determined.

More than half of the patients studied (83) reported a duration of xerostomia of greater than one year, 20 subjects recalling a history in excess of 10 years. Caution is required in the interpretation of this data as the reliability of information based on memory alone is questionable. Patients may recall when they had intermittent oral dryness and not the onset of the chronic phase of xerostomia. For this reason all patients in the study had complained of a daily feeling of dry mouth for a minimum of three months. This is consistent with the criteria for oral dryness in the European classification of Sjögren's syndrome. ${ }^{7}$

Xerogenic medication was considered to be responsible for salivary gland hypofunction in $16(13 \%)$ of patients. The relationship between salivary gland hypofunction and drugs is well recognised. ${ }^{13,14}$ Antidepressants, antihypertensives and antihistamines are the most commonly implicated medications, but it has been estimated that in excess of 400 medications have the capacity to cause oral dryness, and in most cases this effect is thought to be reversible. $^{4,15}$

The cause of salivary gland hypofunction was not identified in $31 \%$ of patients. Psychological factors such as chronic anxiety and depression may have been responsible or contributory to salivary gland hypofunction in some of these patients. It is possible that chronic alcohol abuse was responsible for salivary gland dysfunction in one patient. Undiagnosed systemic disease such as early Sjögren's syndrome, hypothyroidism, hypertension, renal and neurological disorders may also be important in the aetiology of salivary gland hypofunction. ${ }^{14}$ It is not unreasonable therefore, to propose that multiple aetiological 
factors may contribute to salivary gland hypofunction.

Xerostomia is not a reliable predictor of salivary gland hypofunction ${ }^{9}$ and sialometry is not routinely carried out by general medical and dental practitioners at the present time, although the procedure has been recommended for patients complaining of oral dryness. ${ }^{16}$ Generalised (non-oral) signs and symptoms (ocular, skin and vaginal dryness) reported in patients with salivary gland hypofunction are indicative of a reduced exocrine secretion in other parts of the body and the findings in this study are consistent with this statement.

In conclusion, salivary gland hypofunction can have a devastating effect on oral health as well as on the patient's general well being.

1 Fox PC, Van der Ven PF, Sonies BC, Weiffenbach J M, Baum BJ. Xerostomia: evaluation of a symptom with increasing significance. F Am Dent Assoc 1985; 110: 519-25 2 Sreebny LM, Valdini A. Xerostomia: a neglected symptom.

Arch Intern Med 1987; 147: 1333-7.
3 Levine RS. Xerostomia - aetiology and management. Dent Levine RS. Xerostomia - aetio

4 Sreebny LM, Banoczy J, Baum BJ, et al. Saliva: its role in Sreebny LM, Banoczy J, Baum BJ, et al. Saliva: its role in
health and disease. Int Dent $f$ 1992; 42 (suppl 2): 291 - 304. health and disease. Int Dent $\mathcal{F} 1992 ; 42$ (suppl 2): $291-304$. salivary glands in patients with Sjögren's syndrome. Int $\mathcal{f}$ Oral Maxillofacial Surg 1988; 17: 71-5

6 Markusse HM, Pillay M, Breedveld FC. The diagnostic value of salivary gland scintigraphy in patients suspected of primary Sjögren's syndrome. Br $\mathcal{F}$ Rheumatol 1993; 32: $231-5$.

7 Vitali C, Bombardieri S, Moutsopoulos HM, et al. Preliminary criteria for the classification of Sjögren's syndrome. Arthritis Rheum 1993; 36: 340-7.

8 Chilton NW. Design and analysis in dental and oral research. New York: Preager Publications, 1992.
Early recognition is essential and patients complaining of xerostomia should be questioned about other symptoms indicative of reduced oral function, as well as generalised complaints. Patients with clinical signs and symptoms suggestive of generalised exocrine hypofunction should be fully investigated to eliminate systemic disease, such as Sjögren's syndrome. Salivary gland hypofunction is associated with a wide range of oral and nonoral signs and symptom, many of which are strongly suggestive of Sjögren's syndrome. The following are of potential value as clinical triggers to prompt referral for specialist investigation: symptoms of oral dysfunction, dry/ irritable eyes, dry skin, vaginal dryness, reduced lacrimal flow and a history of salivary gland swelling.

9 Fox PC, Busch KA, Baum BJ. Subjective reports of xerostomia and objective measures of salivary gland performance. F Am Dent Assoc 1987; 115: 581 - 4 .

10 Tyldesley WR, Field EA. Oral medicine, Fourth edn. Oxford:Oxford University Press, 1995.

11 Navazesh M, Christensen C, Brightman V. Clinical criteria for the diagnosis of salivary gland hypofunction. $\mathcal{f}$ Dent Res 1992; 71: 1363-9.

12 Weatherall JA, Strong M, Robinson C, Natress BR, Nakagaki H, Main DMG. Determination of volumes of fluid in the mouth by fluoride dilution. Caries Res 1992; 26: 94-7.

13 Sreebny LM, Schwartz SS. A reference guide to drugs and dry mouth. Gerodontology 1986; 5: 75-99.

14 Sreebny LM, Valdini A, Yu A. Xerostomia. Part II: Relationship to nonoral symptoms, drugs, and diseases. Oral Surg Oral Med Oral Pathol 1989; 68: 419-27.

15 Atkinson JC, Fox PC. Salivary gland dysfunction. Clin Geriatr Med 1992; 8: 499-511.

16 Edgar WM, O'Mullane DM. Saliva and dental health. London: BDJ, 1990. 